Dokuz Eylül Üniversitesi-Mühendislik Fakültesi Fen ve Mühendislik Dergisi

Cilt 20, Sayı 59, Mayıs, 2018
Dokuz Eylul University-Faculty of Engineering Journal of Science and Engineering Volume 20, Issue 59, May, 2018

\title{
Manyetoreolojik Sıvı ile El Rehabilitasyon Cihazı Tasarımı ve Üretimi
}

\section{Aysun BALTACI*1, Hasan Aykut AYDIN², Özgen TONAY3 , Barış Oğuz GÜRSES4, Sercan SABANCI ${ }^{5}$, Mustafa ERTEKİN6 ${ }^{6}$, Seçkin ERDEN ${ }^{7}$}

\author{
${ }^{1}$ Ege Üniversitesi, Mühendislik Fakültesi, Makina Mühendisliği Bölümü, 35100, İzmir \\ (ORCID: https://orcid.org/0000-0002-9049-1610) \\ ${ }^{2}$ Ege Üniversitesi, Mühendislik Fakültesi, Makina Mühendisliği Bölümü, 35100, İzmir \\ (ORCID: https://orcid.org/0000-0001-6637-4804) \\ ${ }^{3}$ Ege Üniversitesi, Mühendislik Fakültesi, Makina Mühendisliği Bölümü, 35100, İzmir \\ (ORCID: https://orcid.org/0000-0003-4685-2885) \\ ${ }^{4}$ Ege Üniversitesi, Mühendislik Fakültesi, Makina Mühendisliği Bölümü, 35100, İzmir \\ (ORCID: https://orcid.org/0000-0002-2755-3452) \\ ${ }^{5}$ Ege Üniversitesi, Mühendislik Fakültesi, Makina Mühendisliği Bölümü, 35100, İzmir \\ (ORCID: https://orcid.org/0000-0002-0699-307X) \\ ${ }^{6}$ Ege Üniversitesi, Mühendislik Fakültesi, Tekstil Mühendisliği Bölümü, 35100, İzmir \\ (ORCID: https://orcid.org/0000-0002-5492-7982) \\ ${ }^{7}$ Ege Üniversitesi, Mühendislik Fakültesi, Makina Mühendisliği Bölümü, 35100, İzmir \\ (ORCID: https://orcid.org/0000-0002-8560-3585)
}

(Alınış / Received: 18.09.2017, Kabul / Accepted: 06.11.2017, Online Yayınlanma / Published Online: 15.05.2018)

Anahtar Kelimeler Özet: El rehabilitasyonunun amacı; yaralanmış, ameliyat edilmiş ya Manyetoreoloji, Rehabilitasyon da hastalığa maruz kalmış ellerin ve üst ekstremitelerin, geriye Cihazl,

Manyetik Alan, Medikal Eldiven kalan kullanım kapasitelerini fonksiyonel olarak en yüksek düzeye getirmektir. Bu çalışma ile desteğe ihtiyacı olan, yetersiz ve zayıf kasları ihtiyacı doğrultusunda destekleyerek temel izometrik egzersiz hareketlerini gerçekleştirmek için manyetoreolojik sıvının kullanıldığı bir cihaz geliștirilmiștir.

Manyetoreolojik (MR) akıșkanlar maruz kaldığı manyetik alan ile kısa süre (milisaniye) içinde viskozitesi artmakta ve sıvı, bir katı madde gibi davranmaya başlamaktadır. Manyetik alan uygulanmasına son verildiğinde ise akışkan aynı hızla eski haline dönmektedir.

Bu çalışmanın çıkıș noktası, MR akıșkanların reolojik özelliklerinin manyetik alan ile kontrol edilmesidir. Bu doğrultuda rehabilitasyon gerektiren el ve üst ekstremite vakalarında kasların güçlendirilmesini sağlayacak egzersiz hareketleri, manyetoreolojik sıvının hapsedildiği manyetik alan içerisinde gerçekleştirilebilmektedir. Manyetik alan ile MR sıvısının katılaşması veya yumuşamasıyla el ve parmak hareketleri güçlendirilerek kas gücünün ve fonksiyonel hareketinin arttırılması sağlanmaktadır.

$\mathrm{Bu}$ çalışmada geliştirilen cihaz, içi MR sıvısı ile dolu olan ve çevresindeki sargılar ile üzerine manyetik alanın uygulandığı bir 
Aysun BALTACI, Hasan Aykut AYDIN, Özgen TONAY, Barış Oğuz GÜRSES, Sercan SABANCI, Mustafa ERTEKİN, Seçkin ERDEN /Manyetoreolojik Sıvı ile El Rehabilitasyon Cihazı Tasarımı ve Üretimi

kutudan olușmaktadır. Elektrik akımının kontrolüyle MR sıvının sertlik derecesi, hastanın gelişimine göre ayarlanabilmektedir.

\section{Development of a Magnetorheological Glove Designed for Hand Rehabilitation}

\begin{tabular}{l}
\hline Keywords \\
Magnetorheology, \\
Rehabilitation \\
Device, \\
Magnetic Field, \\
Medical Glove
\end{tabular}

Medical Glove

\begin{abstract}
The aim of hand rehabilitation is to maximize the remaining functional capacities of the hands and upper extremities of injured, operated, or diseased people. This study proposal aims at developing a rehabilitation device, in which magneto-rheological (MR) fluid is used to realize the fundamental isometric exercise motions in order to support the inadequate and weak muscles according to required amount of reaction.

The viscosity of MR fluids increase in miliseconds and the fluid act like a solid. It again returns to its initial state as the application of magnetic field is stopped.

The controllability of the rheological properties of MR fluid via magnetic field forms the starting point of this study: In the cases of hand rehabilitation, exercises needed to strengthen the muscles can be realized by changing the magnitude of the magnetic field of the box in which the MR fluid is stored. Solidification and softening of the MR fluid will force the hand in the glove, which will be placed inside the box.

The study aimed in this study consists of a box with coils attached around and filled with MR fluid under a certain magnetic field. By altering the electromagnetic field, it will be possible to change the hardness of the MR fluid according to the patient's state.
\end{abstract}

*aysun.baltaci@ege.edu.tr

\section{Giriș}

El rehabilitasyonu; parmak, el bilek, ön kol kırıklarında, uzun süren hareketsizlik dönemi sonunda görülebilen eklem sertlikleri, ödem, ağrı, aşırı hassasiyet, adale zayıflı̆̆ bozuklukları gibi sorunların tedavisinde gereklidir. Bunun yanı sıra, sinir tamiri veya tendon transferi sonrası el fonksiyonlarının iyileştirilmesinde, fizik tedavi cihaz ve yöntemleri, egzersiz ve mobilizasyon uygulamaları yapılır ve gerekirse atel ile koruma da sağlanır. Böylece bedensel yetersizliği ve çevreye uyumsuzluğu olan kişinin fiziksel, ruhsal, sosyal ve mesleki potansiyeli en üst düzeye çıkmaktadır.

Üst ekstremitelerin rehabilitasyonu ise fizik tedavi uzmanlarının kontrolünde belirlenen rehabilitasyon hareketlerinin uygulanmasıyla gerçekleştirilmektedir. Teknolojinin gelişmesiyle günümüzde bu ișlemleri gerçekleștiren ve geri bildirim almayı sağlayan robotik sistemler kullanılmaya başlanmıştır. Robotik sistemler geleneksel rehabilitasyon egzersizlerinden farklı 
Aysun BALTACI, Hasan Aykut AYDIN, Özgen TONAY, Barış Oğuz GÜRSES, Sercan SABANCI, Mustafa ERTEKIN, Seçkin ERDEN /Manyetoreolojik Sıvı ile El Rehabilitasyon Cihazı Tasarımı ve Üretimi

olarak, kuvvet uygulayan ve uygun olmayan hareketlerin kısitlandığı sistemler olup eșsiz bir rehabilitasyon ortamı sağlamaktadırlar. Bu sistemler destekleyici sistem tipine göre; aktif, pasif, haptik ve koçluk eden; mekanik tasarımına göre uç aksam bazlı, diş iskelet bazlı ve düzlemsel; eyleyicisine göre (aktüatör yapısına göre): elektriksel aktüatörlü, pnömatik aktüatörlü, hidrolik aktüatörlü, pnömatik yapay kas aktüatörlü, seri elastik aktüatörlü ve fonksiyonel elektriksel kas uyarımlı cihazlar şeklinde sinıflandırılmaktadır [1].

Destekleyici sistem tipine göre aktif cihazlar üst ekstremitelerin aktif hareket desteğini sağlayan ve en az bir aktüatöre sahip olan cihazlardır. Spesifik egzersizleri gerçekleştiremeyecek kadar zayıf olan hastalar için bu sistemler avantaj sağlamaktadır. Pasif cihazlar ise uzuvları hareket ettirmeyen ancak harekete karşı direnç oluşturarak rehabilite eden cihazlardır. Bu cihazlar hareket yeteneğine sahip hastalar için uygun olup herhangi bir aktüatöre sahip olmadıkları için daha hafiftirler. Haptik cihazlar dokunma geri beslemesi fonksiyonuna sahip olan, hareket sağlama ya da harekete karşı koyma gibi özellikleri olmadığı için aktif ya da pasif olarak kategorize edilemeyen cihazlardır. Aktüatöre sahip olmayan koçluk eden cihazlar ise herhangi bir kuvvet üretmeyen, farklı geri besleme sistemlerine sahip cihazlardır [1].

Mekanik tasarımına göre cihazlardan uç aksam bazlı sistemler, diğerlerine kıyasla basit yapıları ve daha az karmaşık kontrol algoritmalarıyla avantajlı sistemlerdir. Ancak bu sistemler kompleks hareketlere sahip olduklarından belirli bir mafsal için spesifik hareketleri izole etmek oldukça güçtür. Uç aksam bazlı sistemlere örnek olarak; "MIT Manus" [2],"ACRE” [3],"CRAME” [4], Takaiwa ve Noritsugu tarafından geliştirilmiş olan sistem
[5],"NeReBot" [6] ve "MACARM" [7] isimli robotlar gösterilebilir. Dış iskelet bazlı sistemler bağımsız ve eş zamanlı kontrollü hareket sağlayan sistemlerdir; ancak hastanın incinmemesi için manipülatörün belirli segmentlerinin uzunlukları iyi ayarlanmalıdır. $\mathrm{Bu}$ nedenle bu sistemlerin belirli bir hasta için kurulumu zaman almaktadır. "ESTEC" diş iskelet sistemi [8] 9 serbestlik derecesine sahip iken IntelliArm [9] 10 serbestliğe sahip rehabilitasyon cihazıdır. El ve parmakların rehabilitasyonu için geliştirilmiş sistemlerde serbestlik derecesi daha da fazla olabilmektedir. Hasegawa ve arkadaşlarının geliştirdiği sistem [10] 11 serbestlik derecesine sahip iken Berlin Teknik Üniversitesi'nin geliştirdiği el dış iskelet rehabilitasyon cihazı [11] ise 20 serbestlik derecesine sahip diş iskelet sistemidir. Düzlemsel robotik cihazlarda ise hareketler sinırl olup sadece belirli bir mafsal ile gerçekleştirilebilen bazı egzersizler için uygundur. $\mathrm{Bu}$ cihazlar düşük maliyetli olup çalışma düzleminin iyi seçildiği durumlarda, hareket aralığı birçok terapötik senaryoya uygun olabilmektedir. Dış aktüatörler yerine vücut kaslarını uyaran aktüatörler de rehabilitasyon amaciyla kullanılmaktadır. Bu amaçla elektriksel kas uyarımından yararlanılmaktadır. Bu cihazlar hafif olup hastanın kaslarını uyararak kas kütlesinin gelişmesini ve kas atrofisinin engellenmesini sağlamaktadır [12].

Üst ekstremite rehabilitasyon cihazlarında eyleyici olarak çoğunlukla elektriksel aktüatörler kullanılmaktadır. Elektrik enerjisinin kolay depolanabilir ve sağlanabilir oluşu ve yüksek güç transferleri bu sistemleri avantajl kılmaktadır. Ticari birçok elekrik motoru ve servo motorlar bu cihazları tahrik etmek için kullanılmaktadır. Aktüatör ile seri olan bir elastik eleman eklemek elektrik motorlarının bu yüksek 
Aysun BALTACI, Hasan Aykut AYDIN, Özgen TONAY, Barış Oğuz GÜRSES, Sercan SABANCI, Mustafa ERTEKIN, Seçkin ERDEN /Manyetoreolojik Sıvı ile El Rehabilitasyon Cihazı Tasarımı ve Üretimi

empedansını hafifletmektedir. Bu da seri elastik aktüatörlü sistemlerin doğmasına sebep olmuştur. Bu sistemler eylemsizliği ve empedansı düşürürken hassas ve stabil kuvvet sağlamakta böylece hasta güvenliğini arttırmaktadır. Ancak sisteme eklenen elastik eleman düşük fonksiyonel bant aralığına sebep olmaktadır. Hidrolik aktüatör sistemleri ağırlık, empedans, akıșkan kaçakları gibi zorlukları nedeniyle tercih edilmemektedir. $\mathrm{Bu}$ sistemler büyük olup ve gürültülü çalışmaktadır [1].

Rehabilitasyon cihazlarında istenen en önemli özellik egzersiz boyunca direnç kuvvetinin büyüklügünün değiștirilebilir olmasidır. Mevcut sistemlerde, ayarlanabilir bir direnç kuvvetinin sağlanması için farklı çözümler uygulanmıştır. $\mathrm{Bu}$ amaçla üzerinde çalışmaların yoğun olarak yapıldığı konulardan biri de manyetoreolojik ya da elektroreolojik akıșkanlar kullanılarak yapılan frenlerdir. $\mathrm{Bu}$ akışkanların reolojik özellikleri (viskozite), üzerine uygulanan elektriksel ya da manyetik alan altında değişmekte ve bu özelliklerinden faydalanılarak yüksek performansa sahip (hızlı ve tekrarlanabilir fren torku) frenlerin oluşturulması mümkün olmaktadır. MR akışkanlar kolloid

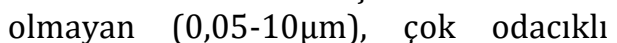
yapıda, yumuşak manyetik taneciklerin organik sıvı ya da su ile karıștırılmasıyla hazırlanmaktadır. MR akışkanlar; manyetik alan olmayan koşullarda Newtonian akışkan gibi davranmaktadırlar. Newton tipi akışkanların deformasyon hızı kayma gerilmesi ile doğru orantılı olup lineerdir ve vizkozitesi sabittir. Bu koşullarda manyetik tanecikler sıvı faz içerisinde rastgele dağılmaktadırlar. Manyetik alan uygulandığında ise, manyetik tanecikler polarize olmakta ve manyetik alan yönüne paralel düzgün çizgiler halinde yeniden konumlanmaktadırlar. Bu sırada milisaniyeler mertebesindeki kısa süreler içinde akıșkanın viskozitesi 105106 kat kadar artmakta ve sıvı adeta katı bir madde gibi davranmaya başlamaktadır. Manyetik alanın artmasıyla akışkan adeta zayıf viskoelastik bir katı haline gelmektedir. Manyetik alan uygulanmasina son verildiğinde ise akışkan aynı hızla eski haline dönmektedir. Akıșkanın eski haline dönmesi için gerekli olan enerji, uygulanan manyetik alanın şiddetiyle artar ve akışkan viskozitesi, manyetik alanın şiddetiyle değişir $[13,14]$. Oda ve arkadaşları çalışmalarında manyetoreolojik akışkanın kullandığı bir "MEM-MRB" isimli izokinetik ve izokontraktil egzersiz makinesi geliștirmişlerdir[15]. Winter ve Bouzit da çalışmalarında, "MRAGES" olarak adlandırdıkları manyetoreolojik akışkanın kullanıldığı kompakt ve fonksiyonel bir haptik cihaz tasarlayıp üretmişlerdir [16].

Bu çalıșmada manyetoreolojik akışkanın kullanıldığı bir el rehabilitasyon cihazının elektromanyetik tasarımı ele alınmıştır. $\mathrm{Bu}$ amaçla öncelikle, farklı sargı tipleri için istenen uniform manyetik akı yoğunluğunu oluşturacak çalışma uzayının boyutlandırılması ve sargı özelliklerinin belirlenmesi için analitik hesaplar yapılmıştır. Yapılan çalışmalar sonucu, uniform manyetik alan elde edebilmek için Helmholtz sargı tipi seçilmiştir. Manyetik alan dağılımı sonlu elemanlar metodu kullanılarak incelenmiştir.

\section{Materyal ve Metot}

\subsection{Mekanik tasarım}

Tasarım aşamasında, eldivenler tam otomatik eldiven makinesi kullanılarak $20 \mathrm{~cm}$ bilek-dirsek mesafesinde ve formu da özel olacak şekilde üretilmiştir (Şekil 1.a). Üretilen eldivenler demir tozu $(0,2$ mikron), sivı silikon MM240TVACC (A ve B bileșenli, 1:10 
Aysun BALTACI, Hasan Aykut AYDIN, Özgen TONAY, Barış Oğuz GÜRSES, Sercan SABANCI, Mustafa ERTEKIN, Seçkin ERDEN /Manyetoreolojik Sıvı ile El Rehabilitasyon Cihazı Tasarımı ve Üretimi

kütlesel karıșım oranında, 12-24 saat kürleşme süresine sahip), içinde mekanik karıștırıcıyla homojenize edilerek demir tozu/silikon karışımına daldırılıp çıkarılarak kaplanmıştır. Eldivenler teflon kaplı alüminyum el profilli üzerine geçirilerek kürleşmeye bırakılmıştır (Şekil 1.b). MR Sıvı doldurulan MR sıvı kutusu ise, gözlem yapma imkanı sağlaması açısından șeffaf malzemeden imal edilmiștir (Şekil 2). Bir önceki aşamada üretilen demir tozu/silikon kaplanmış eldiven de bu düzeneğe ilave edilmiştir. Karbon kumaș ve polimerik kompozitlerinin EMK etkisine sahip olduğu bilinmektedir. Buradan yola çıkarak, MR sıvı kutusunu hapsetmek üzere, karbon/epoksi kompozit malzemeden ilave bir kutu üretilmiştir. $\mathrm{Bu}$ amaçla, öncelikle alüminyum profillerden kutunun iskeleti oluşturulmuştur. Sonrasında, kutunun yüzeylerini oluşturmak için kompozit plakalar imal edilmiştir.

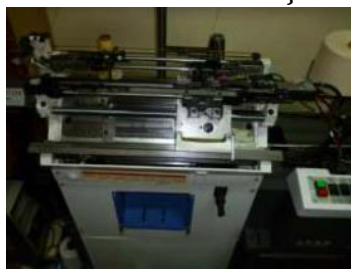

(a)

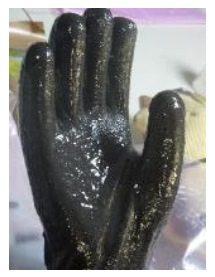

(b)
Şekil 1. (a) JOMDA GD-D tam otomatik bilgisayarlı eldiven makinesi (b) Demir tozu/silikon kaplanmıș eldiven
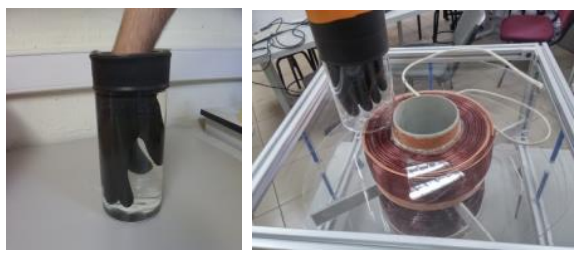

Şekil 2. Üretilen sargı ve MR sıvı kutusu sargıların optimum boyutlarını bulmak için elektromanyetik tasarım yapılmıștır. Tasarımda öncelikle çalışma hacmi ve hacim içerisindeki manyetik akı yoğunluğu belirlenmiștir. Kullanılan MR SIvisının (MRF-132DG) ürün kataloğunda yer alan akma gerilmesimanyetik alan şiddeti grafiğinde, yaklaşık olarak lineer bölgenin son noktasına karşıllık gelen değer 0.2 (T) dır. $\mathrm{Bu}$ nedenle çalışma yüzeyinde manyetik akı yoğunluğu 0.2 (T) olarak hedef alınmıştır. Yapılan literatür çalışmaları sonucunda bulunan formüller ve sargı geometrisi oranları ile analitik hesaplamalar yapılmıștır[17]. Analitik hesaplamalar ile belirlenen çalışma hacmine ve manyetik akı yoğunluğuna ulaşmak için gerekli amper-tur değerleri bulunmuştur. Üç boyutlu sonlu elemanlar çözümleriyle, 3 boyut için manyetik alan dağılımı bulunmuş̧tur.

Analitik çözüm için kullanılan Helmholtz denklemi ve uniform alan için gerekli geometrik oranlar aşağıda verilmiştir (Şekil 3).

$$
\begin{aligned}
& \text { a = Sargıların yarıçapı } \\
& \text { N = Sarım sayısı. } \\
& \text { I = Akım } \\
& \text { z=Seçilen noktanın sargıların ortasına } \\
& \text { olan uzaklığı. } \\
& \text { h = Sargılar arası uzaklık } \\
& \mu 0=\text { Manyetik alan sabiti. } \\
& \vec{B}(z)=\text { Manyetik akı yoğunluğu } \quad \text { z } \\
& \text { yönündeki). }
\end{aligned}
$$

$$
\begin{gathered}
\vec{B}(z)=\frac{\mu_{0} * N * I * a^{2}}{2}\left(\frac{1}{\left(a^{2}+\left(z+\frac{h}{2}\right)^{2}\right)^{3 / 2}}+\right. \\
\left.\frac{1}{\left(a^{2}+\left(z-\frac{h}{2}\right)^{2}\right)^{3 / 2}}\right) \hat{z} \quad(1)
\end{gathered}
$$

\subsection{Elektromanyetik tasarım}

Üretilen rehabilitasyon cihazında, rehabilitasyon için gerekli çalışma hacminde, maksimum homojen manyetik alan oluşturan sargıları ve 
Aysun BALTACI, Hasan Aykut AYDIN, Özgen TONAY, Barış Oğuz GÜRSES, Sercan SABANCI, Mustafa ERTEKİN, Seçkin ERDEN /Manyetoreolojik Sıvı ile El Rehabilitasyon Cihazı Tasarımı ve Üretimi

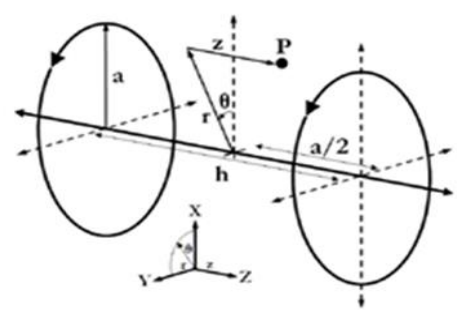

Şekil 3. Maksimum uniform alan için gerekli Helmholtz sargisı geometrisi[17].

Şekilde de görüldüğü gibi sargılar arası uzaklık, sargların yarıçapı uzunluğundadır. Daha önceden belirlenen çalıșma hacmi ve ulașılmak istenen manyetik akı yoğunluğu baz alınarak amper-tur değerine ulaşılmıştır.

Daha düşük akım şiddeti ve sarım sayısında, benzer manyetik akı büyüklüğü ve daha geniş uniform alan uzunluğu elde edebilmek için sargı sayıları arttırılarak yeni tasarımlar oluşturulmuştur (Şekil 4).
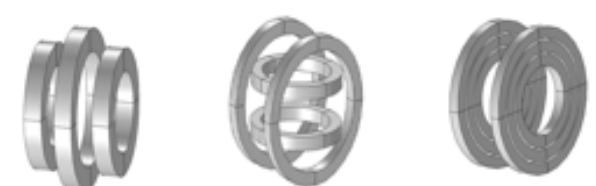

Şekil 4. Sırası ile 3lü 4lü ve 6lı Helmholtz sargisı tasarımları

\section{Bulgular}

\subsection{Sonlu elemanlar analizleri sonucu}

Sonlu elemanlarda manyetik alan analizleri COMSOL'un Magnetic Fields (mf) paket programı kullanılarak yapılmıştır. Yapılan analizlerde, optimal akım, tel kalınlığı, sargı tipi ve sargı sayısına karar verilmiştir. Analiz sonucu elde edilen tasarım parametreleri Tablo 1 de verilmiştir.
Tablo 1. Analizde kullanılan tasarım parametreleri

\begin{tabular}{|l|l|l|}
\hline$\mu 0$ & $\begin{array}{l}1,25664 \mathrm{E} \\
-06\end{array}$ & $\begin{array}{l}\mathrm{kg}^{*} \mathrm{~m} /\left(\mathrm{A}^{*} \mathrm{~s}\right)^{\wedge} \\
2\end{array}$ \\
\hline $\mathrm{N}^{*} \mathrm{I}$ & 40000 & $\mathrm{~A}$ \\
\hline $\mathrm{R}$ & 0,15 & $\mathrm{~m}$ \\
\hline $\mathrm{z}$ & 0 & $\mathrm{~m}$ \\
\hline $\mathrm{d}$ & 0,075 & $\mathrm{~m}$ \\
\hline Bmax (B) & 0,239 & $\mathrm{~T}\left(\mathrm{~Wb} / \mathrm{m}^{\wedge} 2\right)$ \\
\hline
\end{tabular}

Farklı sargı sayısına sahip tasarımların geometrileri Şekil 5-8 de verilmiştir. İncelenen bütün sargı sistemlerinin amper tur sayıları ve kesit alanları eş büyüklükte oluşturulmuştur. Tablo 2 de, bu büyüklükler listelenmiştir.

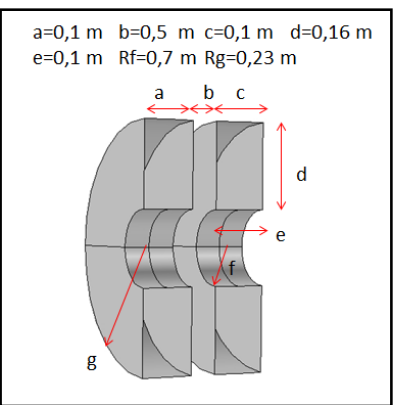

Şekil 5. 2 li Helmholtz sargısı geometrisi

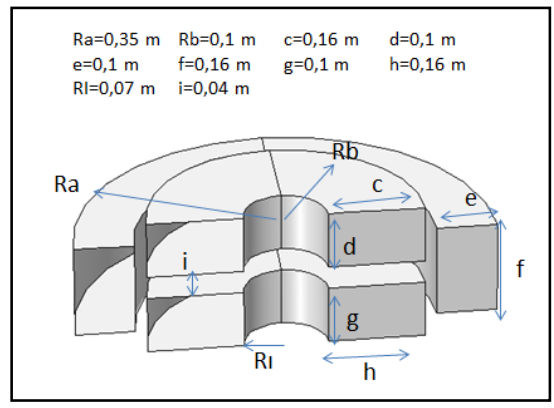

Şekil 6. 3 lü Helmholtz sargısı geometrisi 
Aysun BALTACI, Hasan Aykut AYDIN, Özgen TONAY, Barış Oğuz GÜRSES, Sercan SABANCI, Mustafa ERTEKİN, Seçkin ERDEN /Manyetoreolojik Sıvı ile El Rehabilitasyon Cihazı Tasarımı ve Üretimi

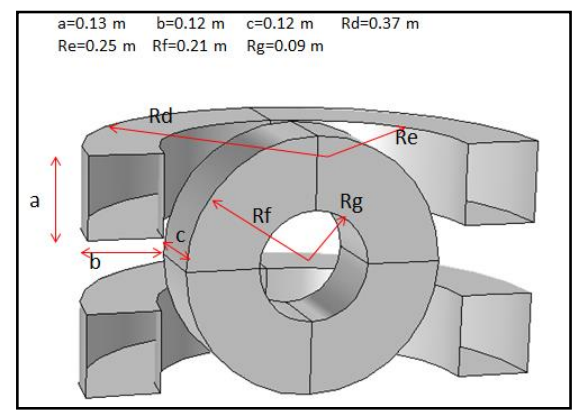

Şekil 7. 4 lü Helmholtz sargısı geometrisi

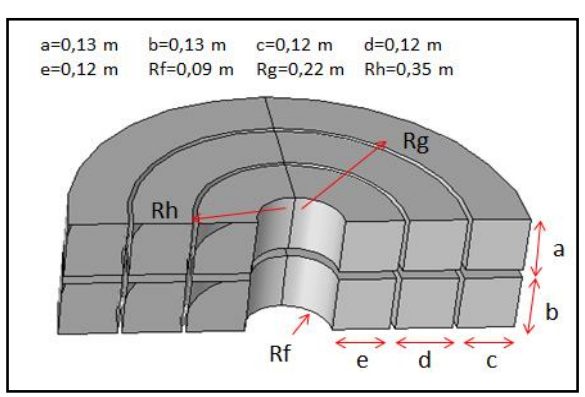

Şekil 8. 6 lü Helmholtz sargısı geometrisi

Tablo 2. İncelenen sargıların genel özellikleri

\begin{tabular}{|c|c|c|}
\hline & $\begin{array}{c}\text { Tek bir sargının } \\
\text { kesit alanı }\end{array}$ & $\begin{array}{c}\text { Bir sargldaki } \\
\text { amper-tur }\end{array}$ \\
\hline 2'li helmholtz & $1600 \mathrm{~mm}^{\wedge} 2$ & 40000 \\
\hline 3'lü helmholtz & $1600 \mathrm{~mm}^{\wedge} 2$ & 40000 \\
\hline 4'lü helmholtz & $1600 \mathrm{~mm}^{\wedge} 2$ & 40000 \\
\hline 6'lı helmholtz & $1600 \mathrm{~mm}^{\wedge} 2$ & 40000 \\
\hline
\end{tabular}

Sargıların sonlu elemanlar analizleri ile eksenler üzerindeki manyetik akı yoğunluğu verileri ve manyetik alan homojenliği bulunmuştur. Homojenlik için;

$H[\%]=\left(\frac{B_{i}-B_{o}}{B_{o}}\right) \times 100$

denklemi kullanılmıştır. Burada $B_{0}$ sargı merkezindeki manyetik akı değerini, $B_{i}$ ise eksen üzerindeki herhangi bir noktadaki manyetik akı değerini göstermektedir. Bu formülle bulunan değerler, çalışma uzayının merkezinden geçen eksenler üzerindeki noktaların homojenlik kalitesini vermektedir. Homojenitesi \%5 den daha iyi olanlar (05), \%5-20 arasinda olanlar (5-20) ve homojenitesi \%20 den daha kötü olanlar (20-100) şeklinde seviyelendirilmiştir. $\mathrm{x}, \mathrm{y}, \mathrm{z}$ eksenleri üzerindeki manyetik akı yoğunluğu ve homojenliğin değişimi Şekil 9-16 da verilmiştir.

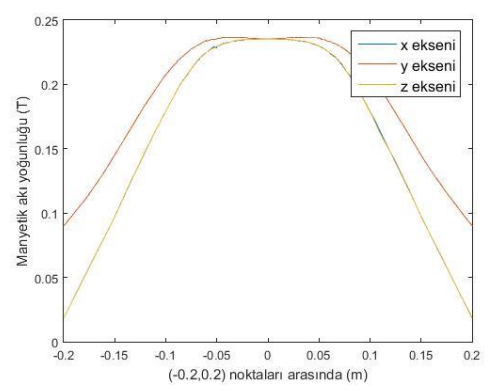

Şekil 9. 2li Helmholtz sargısı eksenlere göre manyetik akı yoğunluğu değișimi

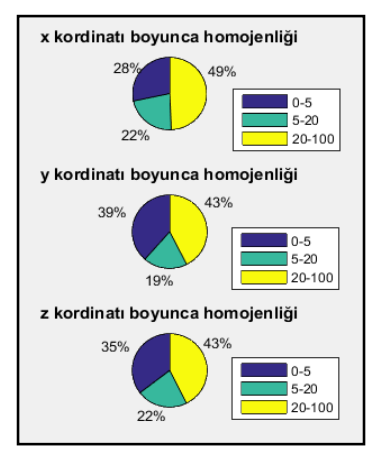

Şekil 10. 2'li Helmholtz sargısı eksenlere göre homojenlik değișimi 
Aysun BALTACI, Hasan Aykut AYDIN, Özgen TONAY, Barış Oğuz GÜRSES, Sercan SABANCI, Mustafa ERTEKİN, Seçkin ERDEN /Manyetoreolojik Sıvı ile El Rehabilitasyon Cihazı Tasarımı ve Üretimi

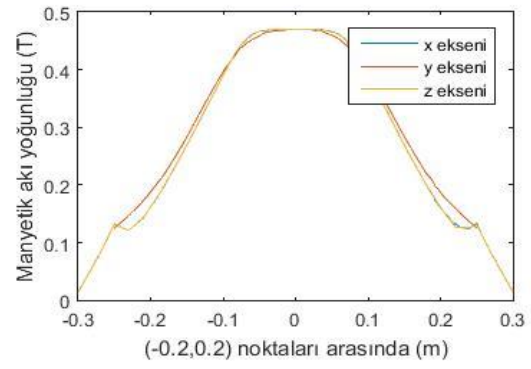

Şekil 11. 3'lü Helmholtz sargısı eksenlere göre manyetik akı yoğunluğu değișimi

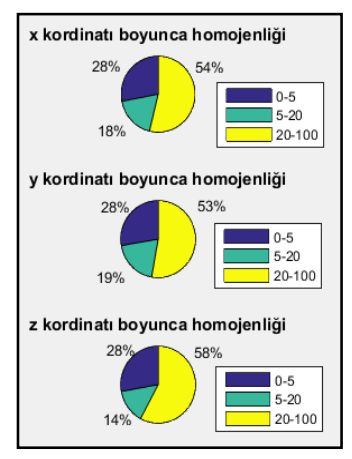

Şekil 12. 3'lü Helmholtz sargısı eksenlere göre homojenlik değişimi

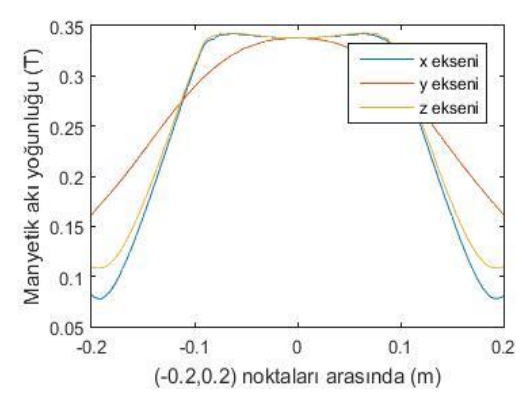

Şekil 13. 4'lü Helmholtz sargısı eksenlere göre manyetik akı yoğunluğu değişimi

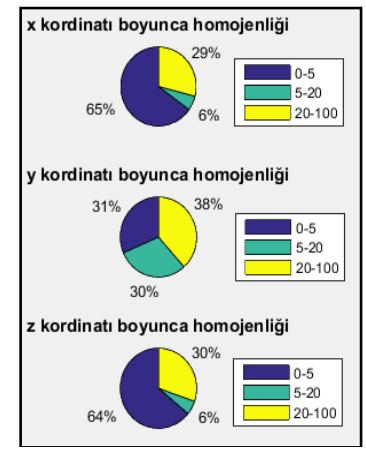

Şekil 14. 4'lü Helmholtz sargısı eksenlere göre homojenlik değişimi

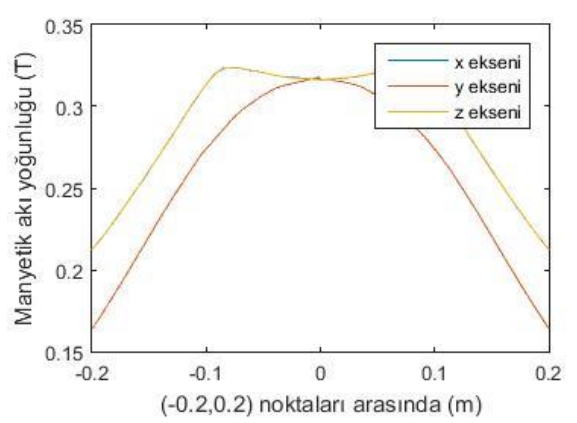

Şekil 15. 6'lı Helmholtz sargısı eksenlere göre manyetik akı yoğunluğu değișimi

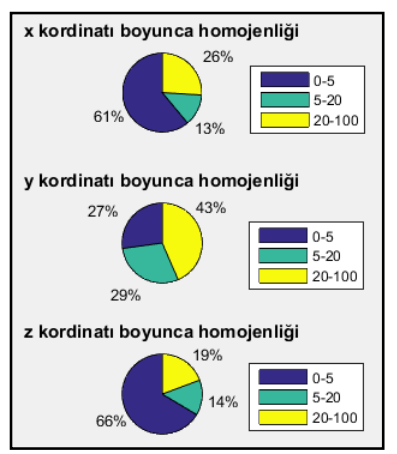

Şekil 16. 6'lı Helmholtz sargısı eksenlere göre homojenlik değișimi

\section{Tartışma ve Sonuç}

Yapılan sonlu elemanlar analizleri sonucu, 3 boyutta uniform manyetik alan için Helmholtz sargısının daha kullanıșlı ve verimli olduğuna karar verilmiştir. 
Aysun BALTACI, Hasan Aykut AYDIN, Özgen TONAY, Barış Oğuz GÜRSES, Sercan SABANCI, Mustafa ERTEKIN, Seçkin ERDEN /Manyetoreolojik Sıvı ile El Rehabilitasyon Cihazı Tasarımı ve Üretimi

Daha düșük akım șiddeti ve sarım sayısında, benzer manyetik akı büyüklüğü elde edebilmek için sargı sayıları arttırılarak, x, y, z eksenleri boyunca daha büyük manyetik akının oluşacağı farklı tasarımlar oluşturulmuştur. 2'li Helmholtz sargıları incelendiğinde, homojenlik değerinin $\mathrm{x}$, $\mathrm{y}, \mathrm{z}$ eksenleri için 53\%, 38\%, 58\% değerleri olarak hesaplandığ görülmektedir. Çalışma uzayı içerisinde $\mathrm{xz}$ düzlemi üzerinde homojenlik değerleri birbirine yakın olsa da, y ekseni üzerindeki dağılım farklıdır. 3'lü Helmholtz sargılarına bakıldığında ise, bu değerlerin 28\%, 27\%, 28\% olarak hesaplandığı dolayısıyla çalışma uzayı içerisindeki homojenliğin üç eksende de birbirine yakın değerlere sahip olduğu görülmektedir. 4 ve 6'lı Helmholtz sarglarında ise y eksenindeki homojenlik 2'li Helmholtz sargılarına benzer bir şekilde diğer iki eksendekine göre daha düşüktür. Manyetoreolojik sıvılarda sıvının akma gerilmesi, manyetik akı yoğunluğu ile değişmektedir. Akma gerilmesi düşük olan sıvilar, içinde oluşturulacak olan harekete (elin hareketi) karşı daha az direnç göstermektedir. Ayrıca, sıvının her bölgesinde akma gerilmelerinin eşit olması, harekete karşı oluşan direnin de her bölgede homojen olmasinı sağlayacaktır. Homojenlik analizleri sonucunda, üç eksendeki homojenliklerin eşit olması açısından 3'lü Helmholtz sargı sistemi daha uygun gibi gözükse de, bu sistemdeki homojenlik değerlerinin \%50'nin altında olması bu çalışmada 2'li Helmholtz sargı sistemi kullanılmasının daha uygun olduğunu göstermiștir.

\section{Teşekkür}

$\mathrm{Bu}$ çalışma, 215M931 nolu TÜBİTAK projesi kapsamında yapılmıştır. Maddi desteklerinden dolayı Türkiye Bilimsel ve Teknolojik Araştırma Kurumu'na teşekkür ederiz.

\section{Kaynakça}

[1] Maciejasz, P., Eschweiler, J., Gerlach-Hahn, K., Jansen-Troy, A. and Leonhardt, S. (2014), "A survey on robotic devices for upper limb rehabilitation", Journal of neuroengineering and rehabilitation, Vol. 11 No. 1, p. 3.

[2] Krebs, H.I., Volpe, B.T., Williams, D., Celestino, J., Charles, S.K., Lynch, D., Hogan, N., 2007. Robot-Aided Neurorehabilitation: A Robot for Wrist Rehabilitation. IEEE Transactions on Neural Systems and Rehabilitation Engineering 15, 327-335. doi:10.1109/TNSRE.2007.903899

[3] Schoone, M., Van Os, P., Campagne, A., 2007. Robot-mediated Active Rehabilitation (ACRE) A user trial, in: Rehabilitation Robotics, 2007. ICORR 2007. IEEE 10th International Conference on. IEEE, pp. 477-481

[4] Spencer, S.J., Klein, J., Minakata, K., Le, V., Bobrow, J.E., Reinkensmeyer, D.J., 2008. A low cost parallel robot and trajectory optimization method for wrist and forearm rehabilitation using the Wii, in: Biomedical Robotics and Biomechatronics, 2008. BioRob 2008. 2nd IEEE RAS \& EMBS International Conference on. IEEE, pp. 869-874.

[5] Takaiwa, M., Noritsugu, T., 2009. Development of wrist rehabilitation equipment using pneumatic parallel manipulator-Acquisition of PT's motion and its execution for patient, in: 
Aysun BALTACI, Hasan Aykut AYDIN, Özgen TONAY, Barış Oğuz GÜRSES, Sercan SABANCI, Mustafa ERTEKİN, Seçkin ERDEN /Manyetoreolojik Sıvı ile El Rehabilitasyon Cihazı Tasarımı ve Üretimi

Rehabilitation Robotics, 2009. ICORR 2009. IEEE International Conference on. IEEE, pp. 34-39.

[6] Rosati, G., Gallina, P., Masiero, S., 2007. Design, Implementation and Clinical Tests of a Wire-Based Robot for Neurorehabilitation. IEEE Transactions on Neural Systems and Rehabilitation Engineering 15, 560-569. doi:10.1109/TNSRE.2007.908560

[7] Beer, R.F., Naujokas, C., Bachrach, B., Mayhew, D., 2008. Development and evaluation of a gravity compensated training environment for robotic rehabilitation of post-stroke reaching, in: Biomedical Robotics and Biomechatronics, 2008. BioRob 2008. 2nd IEEE RAS \& EMBS International Conference on. IEEE, pp. 205-210.

[8] Schiele, A. and Van der Helm, F.C.T. (2006), "Kinematic Design to Improve Ergonomics in Human Machine Interaction", IEEE Transactions on Neural Systems and Rehabilitation Engineering, Vol. 14 No. 4, pp. 456-469.

[9] Ren, Y., Park, H.-S. and Zhang, L.Q. (2009), "Developing a whole-arm exoskeleton robot with hand opening and closing mechanism for upper limb stroke rehabilitation", Rehabilitation Robotics, 2009. ICORR 2009. IEEE International Conference on, IEEE, pp. 761-765.

[10] Perry, J.C., Rosen, J. and Burns, S. (2007), "Upper-Limb Powered Exoskeleton Design", IEEE/ASME Transactions on Mechatronics, Vol. 12 No. 4, pp. 408-417.

[11] Kröger, T. and Wahl, F.M. (Eds.). (2009), Advances in Robotics Research, Springer Berlin Heidelberg, Berlin, Heidelberg, available at: http://link.springer.com/10.1007/978-
3-642-01213-6 (accessed 4 March 2015).

[12] Hamid, S. and Hayek, R. (2008), "Role of electrical stimulation for rehabilitation and regeneration after spinal cord injury: an overview", European Spine Journal, Vol. 17 No. 9, pp. 1256-1269.

[13] Genç, S., 2002. Synthesis and properties of magnetorheological fluids, PhD Thesis, University of Pittsburgh, USA.

[14] Jolly, M.R., Bender, J.W. and Carlson, J.D., Properties and applications of commercial magnetorheological fluids, Thomas Lord Research Center, Lord Corporation.

[15] Oda, K., Isozumi, S., Ohyama, Y., Tamida, K., Kikuchi, T., Furusho, J., 2009. Development of isokinetic and isocontractile exercise machine "MEMMRB" using MR brake, in: Rehabilitation Robotics, 2009. ICORR 2009. IEEE International Conference on. IEEE, pp. 611.

[16] Winter, S.H., Bouzit, M., 2007. Use of Magnetorheological Fluid in a Force Feedback Glove. IEEE Transactions on Neural Systems and Rehabilitation Engineering 15, 2-8. doi:10.1109/TNSRE.2007.891401

[17] Andres F. Restrepo-Alvarez, Edinson Franco-Mejia and Carlos R. Pinedo-Jaramillo 2012. Study and analysis of magnetic field homogeneity of square and circular Helmholtz coil pairs: A Taylor series approximation. Grupo de Investigación en Control Industrial and Grupo de Investigación en Percepción y Sistemas Inteligentes Universidad del Valle, Cali, Colombia. 